\title{
Women with borderline personality disorder expressed they were living with a pejorative label, with self destructive behaviour viewed as manipulative, and with limited access to care
}

Nehls N. Borderline personality disorder: the voice of patients. Res Nurs Health 1999 Aug;22:285-93.

QUESTION: What are the experiences of those who live with the diagnosis of borderline personality disorder?

Design

Qualitative approach grounded in interpretive phenomenology.

\section{Setting}

Crisis intervention service of a community mental health centre, an outpatient mental health clinic, and an acute psychiatric unit

\section{Participants}

30 clients with DSM-III-R or DSM-IV criteria for borderline personality disorder who were receiving mental healthcare services. All participants were economically disadvantaged, adult women.

\section{Methods}

Individual, private interviews were conducted to obtain data about the experience of living with the diagnosis of borderline personality disorder. Each participant was asked to respond to the following question: what does the diagnosis of borderline personality disorder mean to you? If this question did not initiate conversation, the interviewer asked a subsequent question: what is it like for you to live with the diagnosis of borderline personality disorder? Prompts, such as "tell me more," were used throughout the 60 minute interview. The interviews were audiotaped and transcribed verbatim. The data were analysed using the procedures of interpretive phenomenological data analysis.

\section{Main findings}

3 themes were identified: (1) living with a label, (2) living with self destructive behaviour perceived as manipulation, and (3) living with limited access to care. According to participants, providers held preconceived and unfavourable opinions of people with borderline personality disorder. They referred to this experience as being labelled, not diagnosed. Diagnosing had the potential to be helpful, labelling did not. For these participants, the diagnosis of borderline personality disorder was experienced as a pejorative label-a label that perpetuated a sense of being marginalised and potentially mistreated. Self mutilation and suicide attempts were common experiences for participants. The participants encouraged providers to view self harm as a means of managing emotional pain and not as a deliberate attempt to control others. For the participants, access to services and caring professionals was experienced as limited in terms of time and opportunities for meaningful dialogue.

\section{Conclusion}

Women with borderline personality disorder felt they were living with a pejorative label, with self destructive behaviour perceived as manipulative, and with limited access to care.

\section{COMMENTARY}

This qualitative study by Nehls provides important information for clinicians working with people who have received a diagnosis of borderline personality disorder. Much of the literature on borderline personality disorder covers issues of prevalence, ${ }^{1}$ treatment, ${ }^{2}$ and management, ${ }^{3}$ and little attention has been given to the experience of living with the diagnosis. The women interviewed in this study inform us about the meaning they give to having a diagnosis of borderline personality disorder and the stigmatisation that comes with this diagnosis.

Qualitative research seeks to understand a phenomenon by inductive inquiry and focuses on subjectivity - the meanings individuals attribute to aspects of their lives. ${ }^{4}$ There are standards for evaluating this type of research. ${ }^{5}$ Nehls has done an exemplary job of keeping true to the participants' stories by using a multistage method of data analysis that constantly checks interpretations.

This study offers mental health professionals working with individuals diagnosed with a borderline personality disorder insight into the meaning of this diagnosis for the individual. It provides direction for clinicians to consider the label that accompanies this diagnosis, to re-interpret the viewing of self harm as a way of managing emotional pain and not as a control tactic, and, finally, it stresses the importance of meaningful dialogue between the health professional and the person with this diagnosis.

Carolyn Byrne, RN, MHSc McMaster University Hamilton, Ontario, Canada

1 Swartz M, Blazer D, George L, et al. Estimating the prevalence of borderline personality in the community.J Personal Disord 1990;4:257-72.

2 Marziali E, Monroe-Blum H. Interpersonal group psychotherapy for borderline personality disorder. New York, New York: Basic Books, 1994.

3 Dawson DL, MacMillian HL. Relationship management of the borderline patient: from understanding to treatment. New York, New York: Brunner Mazel Books, 1993.

4 Schwandt T. Paths to inquiry in the social disciplines. In: Guba EG, editor. The paradigm dialogue. Newbury Park, California: Sage Publications, 1991:256-76.

5 Altheide DL, Johnson JM. Criteria of assessing interpretative validity in qualitative research. In: Denzin N, Lincoln Y, editors. Handbook of qualitative research. Thousand Oaks, California: Sage Publications, 1994:485-99. 